\title{
Risk of ischemic stroke in patients with ovarian cancer: a nationwide population-based study
}

\author{
Ai-Seon Kuan ${ }^{1,2 \dagger}$, Chung-Jen Teng ${ }^{2,3,4+}$, Hua-Hsi Wu ${ }^{5,6}$, Vincent Yi-Fong Su' ${ }^{2,7}$, Yung-Tai Chen ${ }^{8}$, Sheng-Hsuan Chien ${ }^{9}$, \\ Chiu-Mei Yeh ${ }^{10}$, Li-Yu Hu ${ }^{11}$, Tzeng-Ji Chen ${ }^{3,10}$, Cheng-Hwai Tzeng ${ }^{9}$ and Chia-Jen Liu 2,3,9*
}

\begin{abstract}
Background: Cancer patients are at risk of thromboembolism. However, studies investigating the relationship between ovarian cancer and ischemic stroke are lacking. The objectives of this study were to assess the association between ovarian cancer and ischemic stroke, and to determine the predictive risk factors.

Methods: Ovarian cancer patients aged 20 years and older without antecedent cerebrovascular events and who were followed up for more than 1 year between 1 January 2003 and 31 December 2011 were recruited from the Taiwan National Health Insurance database. Hazard ratios (HRs) of stroke risk for ovarian cancer patients compared with an age- and comorbidity-matched cohort were calculated by Cox proportional regression analysis. The difference in cumulative ischemic stroke incidence between ovarian cancer patients and the matched cohort was analyzed with the Kaplan-Meier method and tested with the log-rank test.

Results: Each cohort (ovarian cancer and matched cohort) consisted of 8,810 individuals, with a median age of 49 years. After a median follow-up of 2.68 and 3.85 years, respectively, the ischemic stroke incidence was 1.38 -fold higher in the ovarian cancer cohort than in the comparison cohort (9.4 versus 6.8 per 1,000 person-years), with an age- and comorbidity-adjusted HR of $1.49(P<0.001)$. The ischemic stroke risk imposed by ovarian cancer was more prominent in patients under 50 years old $(H R 2.28 ; P<0.001)$ compared with patients 50 years and older (HR 1.33; $P=0.005)$. Significant risk factors predicting stroke development were age 50 years and older (HR 2.21; $P<0.001)$, hypertension (HR 1.84; $P<0.001$ ), diabetes mellitus (HR 1.71; $P<0.001)$, and treatment with chemotherapy (HR 1.45; $P=0.017)$, especially platinum-based regimens.
\end{abstract}

Conclusions: Ovarian cancer patients were at an increased risk of developing ischemic stroke. Age, hypertension, diabetes, and chemotherapy treatment were independent risk factors.

Keywords: Chemotherapy, Ischemic stroke, Ovarian cancer, Platinum, Population-based study

\section{Background}

Ovarian cancer is the most common cause of cancer death from gynecologic tumors and is an important global issue requiring further attention [1]. Each year, more than 225,000 new ovarian cancers are diagnosed, and more than 140,000 deaths caused by ovarian cancer are estimated to occur worldwide [2]. The introductions of surgical cytoreduction, platinum-taxane-based chemotherapy, and, most recently, intraperitoneal chemotherapy have

\footnotetext{
* Correspondence: chiajenliu@gmail.com

${ }^{\dagger}$ Equal contributors

${ }^{1}$ Department of Neurosurgery, Neurological Institute, Taipei Veterans General Hospital, Taipei, Taiwan

${ }^{2}$ School of Medicine, National Yang-Ming University, Taipei, Taiwan

Full list of author information is available at the end of the article
}

significantly increased life expectancy with ovarian cancer. Consequently, the median survival for ovarian cancer patients who undergo optimal surgery and adjuvant chemotherapy can be as high as 60 to 110 months [3].

However, the occurrence of comorbidities, such as cerebrovascular complications, after the cancer event may exacerbate mortality in cancer survivors. In addition, the median survival after stroke in cancer patients is 4.5 months, and treatment has no survival benefit [4]. In a large autopsy series, up to $14.6 \%$ of cancer patients had cerebrovascular complications [5]. Cancer and ischemic stroke can cause heavy burdens on the economic and healthcare systems and can disrupt the quality of life in survivors. Therefore, it is very important to identify 
cancer survivors who have a high risk for stroke and to provide them with close surveillance.

In ovarian cancer patients, there are a few studies and reports mentioning the occurrence of stroke [6,7]. However, no large-scale study has examined the association of ovarian cancer and ischemic stroke. Hence, it remains unknown whether ovarian cancer patients exhibit an elevated risk of developing ischemic stroke compared with the general population. Therefore, a population-based cohort study using the Taiwan National Health Insurance (NHI) was conducted to examine this issue.

\section{Methods}

\section{Data sources}

Taiwan's NHI program is a universal healthcare program that was implemented in 1995. It currently covers more than $99.5 \%$ of the entire population [8]. Data used in this study were obtained from the research database of NHI, which contains encrypted computerized medical claims, inpatient and ambulatory care records, data from the Registry for Catastrophic Illness Patients (RCIP), basic demographic information, and other healthcare data. The accuracy of diagnoses in this database has been validated for several diseases, including ischemic stroke [9]. Diseases were coded with the cancer International Classification of Diseases, Ninth Revision, Clinical Modification (ICD-9-CM) diagnosis codes, 2001 edition. Because the Taiwan NHI research database contains encrypted computerized data for research purposes, the ethics committee of Taipei Veterans General Hospital informed us that this study was exempt from full review and that informed consent from each patient was not required.

\section{Study subjects}

Two cohorts, an ovarian cancer cohort and a matched control cohort, were enrolled in this study. The ovarian cancer cohort (ICD-9-CM code 183.X) was identified from the RCIP. For a patient to be enrolled in the RCIP, the diagnosis of ovarian cancer had to be confirmed by histology. The diagnosis was subject to periodic review by the Bureau of NHI. Patients with a new ovarian cancer diagnosis made between 1 January 2003 and 31 December 2011 were included in this study. Subjects younger than 20 years old, those who had been diagnosed with any cerebrovascular disease before ovarian cancer diagnosis, and those who were lost to follow-up were excluded. Each individual in the ovarian cancer group was matched on the basis of age, gender, time of enrollment, and comorbidities related to cerebrovascular events with an individual without ovarian cancer in a comparison cohort, which was also selected from the NHI.

\section{Outcome measures}

Occurrence of ischemic stroke was identified after the initial diagnosis of ovarian cancer using medical claims data in the NHI. Ischemic stroke identification using data in the Taiwan NHI is highly accurate compared to other insurance databases and is valid for population-based research [9]. In our study, identification was made on the basis of ischemic stroke coding (ICD-9-CM code 436, 433. $\mathrm{X}, 434 . \mathrm{X}$, and 437.1X) accompanied by computed tomographic or magnetic resonance images. Diagnoses lacking confirmatory image were not included. Subjects in both cohorts (ovarian cancer and matched) were followed until a diagnosis of ischemic stroke was made, death occurred, 31 December 2011 was reached, or the patient withdrew from the NHI.

\section{Statistical analyses}

Microsoft SQL Server 2012 (Microsoft Corporation, Redmond, WA, USA) and SAS 9.2 software (SAS Institute Inc., Cary, NC, USA) were used for data management and analysis. All statistical analyses were performed using SPSS statistical software version 17.0 for Window (SPSS, Inc., Chicago, IL, USA). Statistical significance was defined as a $P$ value less than 0.05 .

The demographic and clinical characteristics of ovarian cancer patients and matched cohorts are presented as the total number (n) and proportion (\%). Continuous and categorical variables were compared between groups with the Mann-Whitney $U$ test and Pearson's chi-squared test, as appropriate. To assess the effect of age, study subjects were divided into two subgroups: age $<50$ years and age $\geq 50$ years. Hazard ratio (HR) and $95 \%$ confidence intervals $(\mathrm{CI})$ were calculated with the Cox proportional hazard models to test the association between ovarian cancer and ischemic stroke; the HR was further adjusted for age and comorbidities. The difference in the cumulative incidence of ischemic stroke between the ovarian cancer patient cohort and the matched cohort was calculated with the Kaplan-Meier method and tested with the log-rank test.

Conventional risk factors for stroke, such as diabetes mellitus and hypertension, which are also possible confounding factors, were further assessed for their effects on the association of ovarian cancer and subsequent ischemic stroke in univariate Cox proportion hazards models. Additionally, therapeutic modalities, such as surgery and chemotherapy, were put into Cox models as timedependent covariates to avoid immortal time bias. All risk factors with $P$ values $<0.1$ in the univariate model were further entered into the multivariate analysis.

\section{Results}

\section{Clinical characteristics of the study population}

A total of 10,182 patients with ovarian cancer diagnosed between 1 January 2003 and 31 December 2011 were identified. Patients who were younger than 20 years old $(n=277)$, diagnosed with cerebrovascular disease before ovarian cancer diagnosis $(n=1,091)$, or lost to follow-up 
( $n=4)$ were excluded. In total, 8,810 ovarian cancer patients were included in the study (Figure 1). The demographic characteristics of the study group and matched cohort (1:1 ratio of patient number) are shown in Table 1.

All subjects in both groups were women with similar age and comorbidity distributions. The median age was 49 years for both cohorts (interquartile range (IQR), 41 to 58 years). The most common comorbidity was hypertension (27.5\%). There was no difference in cerebrovascular event-related comorbidities between the two groups. In the ovarian cancer cohort, 6,160 patients (69.9\%) received surgery, and 6,590 patients $(74.8 \%)$ received chemotherapy.

\section{Incidence of ischemic stroke and risk factors}

The median follow-up duration was 2.68 years (IQR, 1.44 to 4.98 years) for the ovarian cancer group and 3.85 years (IQR, 1.83 to 6.14 years) for the matched cohort group. During the follow-up period, there were 267 (9.4 per 1,000 person-years) new onset ischemic strokes in the study cohort and 244 (6.8 per 1,000 person-years) in the matched cohort. The incidence of ischemic stroke after the time of enrollment increased with age in both cohorts. The log-rank test showed a higher cumulative incidence of ischemic stroke in the ovarian cancer group than in the matched cohort $(P<0.001)$ (Figure 2$)$.

Compared with the matched cohort, the crude HR for subsequent ischemic stroke after ovarian cancer was 1.38 (95\% CI, 1.16 to $1.64 ; P<0.001$ ). After adjusting for age and comorbidities, the HR was 1.49 (95\% CI, 1.25 to 1.78 ; $P<0.001)$. When the study subjects were stratified into two subgroups, the relative risk (RR) of stroke was higher $(P<0.05)$ in subjects who were $<50$ years (adjusted HR 2.28; $95 \%$ CI, 1.55 to 3.36 ; $P<0.001$ ) compared with those who were $\geq 50$ years old (adjusted HR 1.33; 95\% CI, 1.09 to $1.62 ; P=0.005$ ) (Table 2).

In the multivariate Cox proportion hazards model, factors independently determining the risk of subsequent ischemic stroke in ovarian cancer patients included age $\geq 50$ years (HR 2.21; 95\% CI, 1.64 to 2.99; $P<0.001$ ), diabetes mellitus (HR 1.71; 95\% CI, 1.27 to $2.29 ; P<0.001$ ), hypertension (HR 1.84; $95 \%$ CI, 1.39 to $2.43 ; P<0.001$ ), and chemotherapy treatment (HR 1.45; 95\% CI, 1.07 to $1.97 ; P=0.017$ ) (Table 3 ). Similarly, age $\geq 50$ years, diabetes mellitus, and hypertension were also independent risk factors for ischemic stroke in the control cohort (Additional file 1: Table S1). Comparing different chemotherapy modalities, cisplatin-based (HR 1.38; 95\% CI, 1.07 to $1.76 ; P=0.012$ ) and carboplatin-based regimens (HR 1.46; 95\% CI, 1.13 to $1.89 ; P=0.004$ ) were independent risk factors for subsequent ischemic stroke, whereas non-platinum-based regimens (HR 1.12; 95\% CI, 0.61 to $2.04 ; P=0.722$ ) were not. These risk factors remained significant when 16 patients who had a new diagnosis of brain metastasis (ICD-9-CM code 198.3) less than three months after the stroke event were censored for analysis, to avoid a short-term misclassification during acute brain insults (Additional file 1: Table S2 and S3).

\section{Discussion}

This is the first population-based study to determine the risk of new onset ischemic stroke after an ovarian cancer diagnosis. Our data revealed an increased risk of developing ischemic stroke with an adjusted HR of 1.49 among patients with ovarian cancer. Significant risk factors for ischemic stroke included age $\geq 50$ years, diabetes mellitus, hypertension, and chemotherapy treatment.

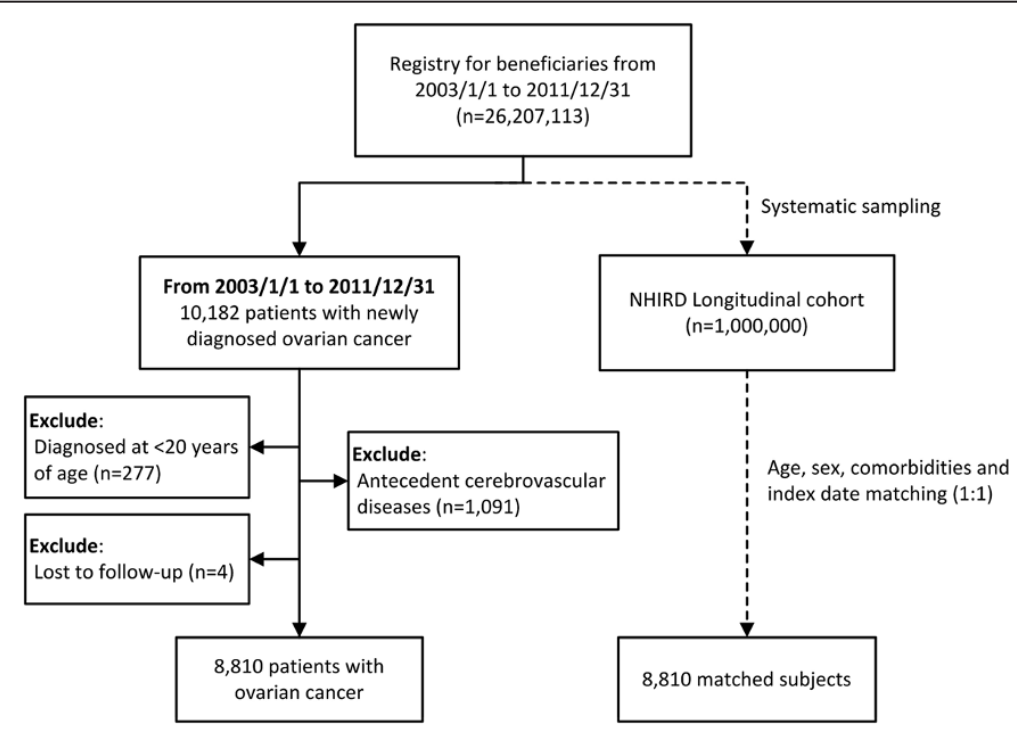

Figure 1 Participant selection flow chart. 
Table 1 Baseline patient characteristics of subjects with and without ovarian cancer

\begin{tabular}{|c|c|c|c|c|c|}
\hline \multirow[t]{2}{*}{ Demographic data } & \multicolumn{2}{|c|}{$\begin{array}{l}\text { Subjects with ovarian cancer } \\
\qquad n=8,810\end{array}$} & \multicolumn{2}{|c|}{$\begin{array}{l}\text { Subjects without ovarian cancer } \\
\qquad n=8,810\end{array}$} & \multirow[t]{2}{*}{$P$} \\
\hline & $n$ & $\%$ & $\mathrm{n}$ & $\%$ & \\
\hline Age (interquartile range) & 49 (41 to 58$)$ & & 49 (41 to 58$)$ & & 1.000 \\
\hline$\geq 50$ years & 4,357 & 49.5 & 4,357 & 49.5 & 1.000 \\
\hline$<50$ years & 4,453 & 50.5 & 4,453 & 50.5 & \\
\hline \multicolumn{6}{|l|}{ Comorbidities } \\
\hline Diabetes mellitus & 1,446 & 16.4 & 1,447 & 16.4 & 0.984 \\
\hline Hypertension & 2,425 & 27.5 & 2,426 & 27.5 & 0.987 \\
\hline Chronic kidney disease & 709 & 8.0 & 708 & 8.0 & 0.978 \\
\hline Dyslipidemia & 1,987 & 22.6 & 1,986 & 22.5 & 0.986 \\
\hline Coronary artery disease & 52 & 0.6 & 50 & 0.6 & 0.843 \\
\hline Atrial fibrillation & 47 & 0.5 & 45 & 0.5 & 0.834 \\
\hline Peripheral arterial occlusive disease & 19 & 0.2 & 17 & 0.2 & 0.739 \\
\hline \multicolumn{6}{|l|}{ Treatment } \\
\hline Surgery & 6,160 & 69.9 & & & \\
\hline Chemotherapy & 6,590 & 74.8 & & & \\
\hline Cisplatin-based & 3,093 & 35.1 & & & \\
\hline Carboplatin-based & 5,041 & 57.2 & & & \\
\hline Non-platinum-based & 402 & 4.6 & & & \\
\hline
\end{tabular}

Up to $40 \%$ of stroke cases in cancer are cryptogenic related, possibly induced by the underlying malignancy [10]. For cancer patients, RRs of developing venous thrombosis of four- to seven-fold have been reported compared with matched controls [11]. However, cancer is a broad disease and different types of cancer may have different risks. Generally, pancreas, brain, lung, and ovarian cancers have been associated with the higher risks of developing venous thrombosis [12]. In addition, the presence of disseminated intravascular coagulation in patients with ovarian cancer may indicate a hypercoagulative status [13]. One direct evidence for the hypercoagulative state is the frequently overexpressed tissue factor in ovarian cancer tissue, which could activate the extrinsic coagulation cascade and cause thrombolic events in ovarian cancer patients [14].

Although the temporal-causal relationship between ovarian cancer progression and hypercoagulation is unknown, high levels of coagulation factors and associated regulatory proteins have been observed in ovarian cancer patients $[15,16]$. Increased levels of circulating mucinous material

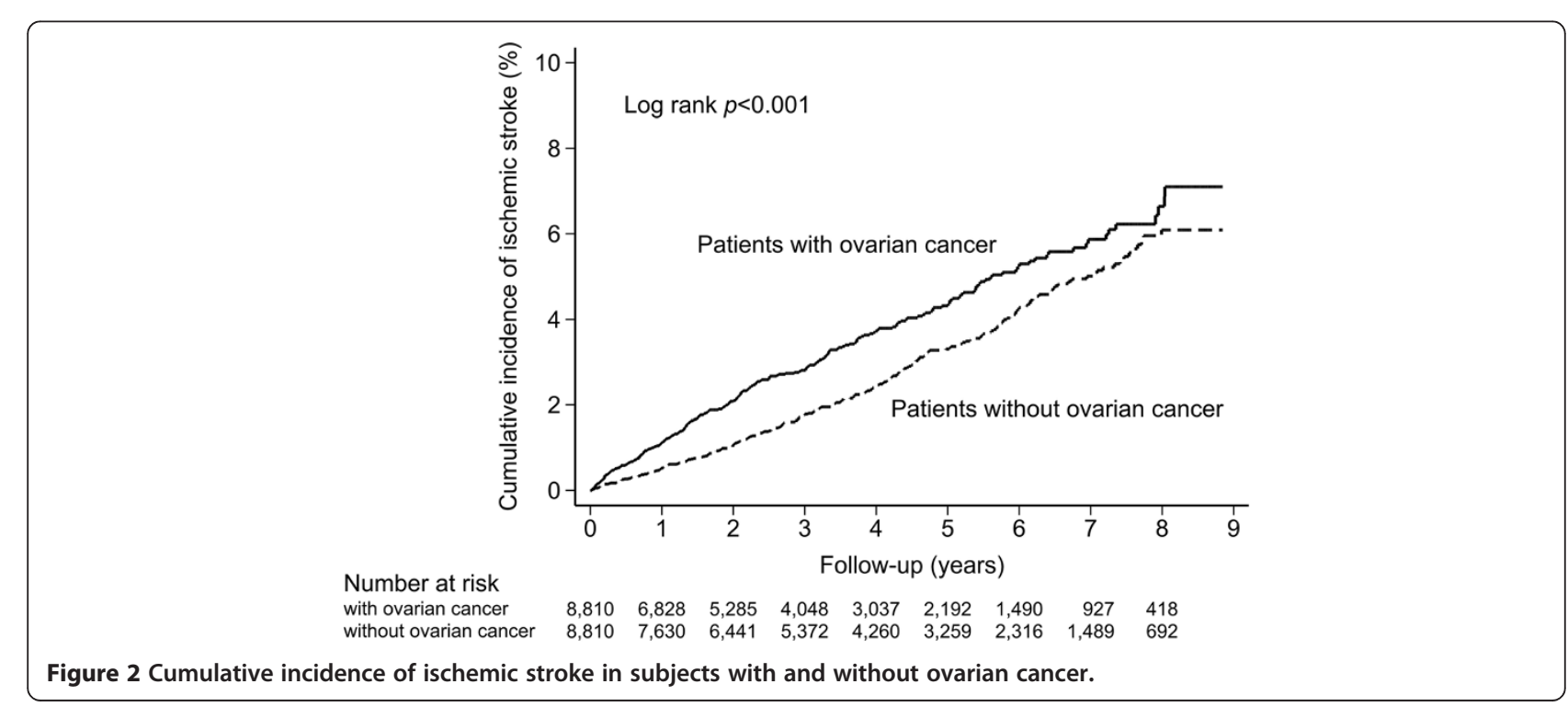


Table 2 Incidence of ischemic stroke in subjects with and without ovarian cancer

\begin{tabular}{|c|c|c|c|c|c|c|c|c|}
\hline & \multicolumn{2}{|c|}{ Patients with ovarian cancer } & \multicolumn{2}{|c|}{ Patients without ovarian cancer } & \multirow{2}{*}{$\begin{array}{c}\text { Crude HR } \\
(95 \% \mathrm{Cl})\end{array}$} & \multirow[t]{2}{*}{$P$} & \multirow{2}{*}{$\begin{array}{l}\text { Adjusted } \mathrm{HR}^{\mathrm{a}} \\
\quad(95 \% \mathrm{Cl})\end{array}$} & \multirow[t]{2}{*}{$P$} \\
\hline & $\begin{array}{c}\text { Number of } \\
\text { ischemic stroke }\end{array}$ & $\begin{array}{c}\text { Per } 1,000 \\
\text { person-years }\end{array}$ & $\begin{array}{c}\text { Number of } \\
\text { ischemic stroke }\end{array}$ & $\begin{array}{c}\text { Per } 1,000 \\
\text { person-years }\end{array}$ & & & & \\
\hline Total & 267 & 9.4 & 244 & 6.8 & $1.38(1.16$ to 1.64$)$ & $<0.001$ & 1.49 (1.25 to 1.78$)$ & $<0.001$ \\
\hline \multicolumn{9}{|l|}{ Age } \\
\hline$\geq 50$ years & 192 & 15.5 & 205 & 12.1 & 1.29 (1.06 to 1.57$)$ & 0.012 & 1.33 (1.09 to 1.62$)$ & 0.005 \\
\hline$<50$ years & 75 & 4.7 & 39 & 2.1 & 2.27 (1.54 to 3.34$)$ & $<0.001$ & 2.28 (1.55 to 3.36$)$ & $<0.001$ \\
\hline
\end{tabular}

${ }^{a}$ Adjusted for age, sex, and comorbidities. $\mathrm{Cl}$, confidence interval; HR, hazard ratio.

produced by ovarian tumors might play a role in intravascular hypercoagulation and hyperviscosity [17]. Together, these findings suggest that a subgroup of ovarian cancer patients may have distinct coagulopathies, making these patients vulnerable for specific vascular events, including ischemic stroke. These findings may also explain why ovarian cancer survivors in our study, especially younger patients who had no established conventional stroke risk factors, possessed a higher risk of subsequent ischemic stroke.

The most well-known and medically important (that is, treatable) risk factors for ischemic stroke include hypertension, diabetes mellitus, dyslipidemia, smoking, and obesity [18]. Although lifestyle and obesity were not included in the present analysis, some epidemiological studies have demonstrated that hypertension and diabetes are significant risk factors for stroke in several cancers $[19,20]$. Our multivariate analyses revealed a similar result, with additional significant risk factors, including age $\geq 50$ years old and chemotherapy treatment. These results suggest that conventional stroke risk factors remain important in the pathogenesis of stroke in ovarian cancer patients.

Our study showed that ovarian cancer patients receiving chemotherapy, particularly platinum-based regimens, might have an additionally increased stroke risk. This effect was insignificant in non-platinum-based regimens. In prior studies, chemotherapy-associated increased stroke was observed in patients with head-and-neck cancer $[19,21]$, breast cancer [22], and urothelial carcinoma [23]. While the mechanism is still uncertain, some suggested pathophysiologies are associated with increased fibrinopeptide A and decreased fibrinolytic activity [24], elevated plasma von Willebrand factor [25], hypomagnesiumassociated vascular spasm [26,27], endothelial injury $[28,29]$, and mononuclear cell-mediated platelet activation [30]. Moreover, Li et al. demonstrated that platinum in a chemotherapy regimen, which is also commonly used for treating ovarian cancer patients, may increase the risk of ischemic stroke among cancer patients [31]. Cerebral

Table 3 Analyses of risk factors for ischemic stroke in patients with ovarian cancer

\begin{tabular}{|c|c|c|c|c|}
\hline \multirow[t]{2}{*}{ Predictive variables } & \multicolumn{2}{|c|}{ Univariate analysis } & \multicolumn{2}{|c|}{ Multivariate analysis $^{a}$} \\
\hline & HR (95\% Cl) & $P$ & $\mathrm{HR}(95 \% \mathrm{Cl})$ & $P$ \\
\hline Age $\geq 50$ & 3.25 (2.49 to 4.25$)$ & $<0.001$ & $2.21(1.64$ to 2.99$)$ & $<0.001$ \\
\hline \multicolumn{5}{|l|}{ Comorbidities } \\
\hline Diabetes mellitus & 2.84 (2.19 to 3.67$)$ & $<0.001$ & $1.71(1.27$ to 2.29$)$ & $<0.001$ \\
\hline Hypertension & 3.15 (2.47 to 4.00$)$ & $<0.001$ & $1.84(1.39$ to 2.43$)$ & $<0.001$ \\
\hline Chronic kidney disease & 1.64 (1.12 to 2.39$)$ & 0.011 & $1.05(0.71$ to 1.56$)$ & 0.791 \\
\hline Dyslipidemia & 2.25 (1.75 to 2.89$)$ & $<0.001$ & $1.09(0.81$ to 1.46$)$ & 0.569 \\
\hline Coronary artery disease & 3.66 (1.36 to 9.83$)$ & 0.010 & $2.01(0.74$ to 5.42$)$ & 0.169 \\
\hline Atrial fibrillation & 0.75 (0.11 to 5.31$)$ & 0.769 & & \\
\hline Peripheral arterial occlusive disease & 3.09 (0.43 to 22.02) & 0.261 & & \\
\hline \multicolumn{5}{|l|}{ Treatment $^{\mathrm{b}}$} \\
\hline Surgery ${ }^{c}$ & $0.83(0.64$ to 1.06$)$ & 0.138 & & \\
\hline Chemotherapy & $1.67(1.25$ to 2.25$)$ & 0.001 & $1.45(1.07$ to 1.97$)$ & 0.017 \\
\hline Cisplatin-based & $1.35(1.06$ to 1.73$)$ & 0.017 & $1.38(1.07$ to 1.76$)$ & 0.012 \\
\hline Carboplatin-based & $1.76(1.37$ to 2.25$)$ & $<0.001$ & $1.46(1.13$ to 1.89$)$ & 0.004 \\
\hline Non-platinum-based & 1.24 (0.68 to 2.26$)$ & 0.490 & $1.12(0.61$ to 2.04$)$ & 0.722 \\
\hline
\end{tabular}

${ }^{a}$ All factors with $P<0.1$ in univariate analyses were included in the Cox multivariate analysis; ${ }^{b}$ treatment was analyzed as a time-dependent covariate in the Cox regression model; ${ }^{c}$ surgery included unilateral or bilateral salpingo-oophorectomy, or debulking surgery. $\mathrm{Cl}$, confidence interval; $\mathrm{HR}$, hazard ratio. 
infarction after cisplatin-based chemotherapy in ovarian cancer patients has also been reported previously [32,33]. A meta-analysis of 38 randomized phase II and III trials showed that cancer patients who received cisplatin-based chemotherapy demonstrated a dose-dependently increased risk (RR $1.67,95 \% \mathrm{CI}, 1.25$ to 2.23 ; $P=0.01$ ) of thromboembolism compared with patients who received a noncisplatin-based regimen [34]. More research is needed to clarify the role of chemotherapy in the relationship of ovarian cancer and subsequent ischemic stroke, as well as to determine whether it is necessary to use a prophylactic antiplatelet agent in high-risk patients during the chemotherapy period.

Our study revealed that ovarian cancer patients appeared to have a higher risk of stroke soon after cancer diagnosis, and the increased risk persisted throughout the follow-up period. A similar phenomenon was also observed in survivors of head-and-neck cancer [19,21], cervical cancer [35], breast cancer [36], and Hodgkin lymphoma [37]. The stroke risk imposed by ovarian cancer seemed to be more prominent in people of younger age, with adjusted HRs of 2.28 and 1.33 in the age groups of $<50$ years and $\geq 50$ years, respectively. These findings suggest that, with increasing age, the age factor becomes more important than cancer as a risk factor of stroke.

This study has several limitations. First, lifestyle variables and behavioral factors, such as tobacco and alcohol use, body mass index, dietary habits, and biochemistry profiles including serum D-dimer level and disseminated intravascular coagulation profiles, were not available in the claims data of the Taiwan NHI. Second, cancer staging and histology were not available in this database, and their association with ischemic stroke could not be identified. Finally, information on the cause of death was not available; consequently, we cannot determine the impact of stroke on cancer-related mortality. Despite these limitations, our study was based on a nationwide, population-based database that could identify all cases of ovarian cancer and ischemic stroke in the study period. The large sample size in our study contributed to substantial statistical power and revealed a clear association between ovarian cancer and ischemic stroke, with subtle statistically significant differences between the two cohorts.

\section{Conclusions}

This nationwide population-based study demonstrated that ovarian cancer patients are at an increased risk of subsequent ischemic stroke. Significant risk factors included age $\geq 50$ years, hypertension, diabetes mellitus, and chemotherapy treatment, especially platinum-based regimens, following a diagnosis of ovarian cancer. With the longer expected life span of ovarian cancer patients, close surveillance and proper stroke-prevention strategies may be needed. Further prospective clinical studies of the relationship between ovarian cancer and ischemic stroke are warranted.

\section{Additional file}

Additional file 1: Table S1. Analyses of risk factors for ischemic stroke in patients without ovarian cancer. Table S2. Incidence of ischemic stroke in patients with and without ovarian cancer (excluding those with brain metastasis within 3 months after stroke). Table S3. Analyses of risk factors for ischemic stroke in patients with ovarian cancer (excluding those with brain metastasis less than 3 months after a stroke).

\section{Abbreviations}

Cl: confidence interval; HR: hazard ratio; ICD-9-CM: International Classification of Diseases, Ninth Revision, Clinical Modification; IQR: interquartile range; NHI: National Health Insurance; RCIP: Registry for Catastrophic Illness Patients; $\mathrm{RR}$ : relative risk.

\section{Competing interests}

The authors declare that they have no competing interests.

\section{Authors' contributions}

ASK and CJL had full access to all of the data in the study and take responsibility for the integrity of the data and the accuracy of the data analysis. ASK, CJT, and CJL designed the study. CMY and CJL acquired the data and performed statistical analysis. ASK, CJT, HHW, TJC, and CHT gave the final interpretation of the results. ASK and CJT drafted the manuscript. CJT, HHW, WYS, YTC, SHC, and LYH gave critical revision of the manuscript for important intellectual content. CMY, TJC and CHT gave administrative, technical, and material support. TJC, CHT and CJL were the study supervisors. $C J \mathrm{~L}$ acts as guarantor and accepts responsibility for the integrity of the work as a whole. All authors read and approved the final manuscript.

\section{Acknowledgements}

This study is supported in part by a grant from Taipei Veterans General Hospital (V103B-022 and V103E10-001). The supporting sources have no role in the study design or conduct, or in the decision to submit for publication. The study is based on data from the National Health Insurance Research Database provided by the Bureau of National Health Insurance (BNHI), Department of Health, Executive Yuan, Taiwan and managed by National Health Research Institutes (NHRI), Taiwan. We express our particular gratitude to the government organization $\mathrm{BNHI}$ and the non-profit foundation NHRI.

\section{Author details}

${ }^{1}$ Department of Neurosurgery, Neurological Institute, Taipei Veterans General Hospital, Taipei, Taiwan. ${ }^{2}$ School of Medicine, National Yang-Ming University, Taipei, Taiwan. ${ }^{3}$ Institute of Public Health, National Yang-Ming University, Taipei, Taiwan. ${ }^{4}$ Division of Oncology and Hematology, Department of Medicine, Far Eastern Memorial Hospital, New Taipei City, Taiwan. ${ }^{5}$ Institute of Clinical Medicine, School of Medicine, National Yang-Ming University, Taipei, Taiwan. ${ }^{6}$ Department of Obstetrics \& Gynecology, Taipei Veterans General Hospital, Taipei, Taiwan. ${ }^{7}$ Department of Chest Medicine, Taipei Veterans General Hospital, Taipei, Taiwan. ${ }^{8}$ Department of Medicine, Taipei City Hospital Heping Fuyou Branch, Taipei, Taiwan. ${ }^{9}$ Division of Hematology and Oncology, Department of Medicine, Taipei Veterans General Hospital, Taipei, Taiwan. ${ }^{10}$ Department of Family Medicine, Taipei Veterans General Hospital, Taipei, Taiwan. ${ }^{11}$ Department of Psychiatry, Kaohsiung Veterans General Hospital, Kaohsiung, Taiwan.

Received: 10 January 2014 Accepted: 25 February 2014 Published: 25 March 2014

\section{References}

1. 1999-2010 cancer incidence and mortality data. apps.nccd.cdc.gov/uscs/.

2. Jemal A, Bray F, Center MM, Ferlay J, Ward E, Forman D: Global cancer statistics. CA Cancer J Clin 2011, 61:69-90.

3. Landrum LM, Java J, Mathews CA, Lanneau GS Jr, Copeland LJ, Armstrong DK, Walker JL: Prognostic factors for stage III epithelial ovarian cancer 
treated with intraperitoneal chemotherapy: a gynecologic oncology group study. Gynecol Oncol 2013, 130:12-18.

4. Cestari DM, Weine DM, Panageas KS, Segal AZ, DeAngelis LM: Stroke in patients with cancer: incidence and etiology. Neurology 2004, 62:2025-2030.

5. Graus F, Rogers LR, Posner JB: Cerebrovascular complications in patients with cancer. Medicine (Baltimore) 1985, 64:16-35.

6. Borowski A, Ghodsizad A, Gams E: Stroke as a first manifestation of ovarian cancer. J Neurooncol 2005, 71:267-269.

7. Sanderson A, Bonington SC, Carrington BM, Alison DL, Spencer JA: Cerebral metastasis and other cerebral events in women with ovarian cancer. Clin Radiol 2002, 57:815-819.

8. Universal health coverage in Taiwan. www.nhi.gov.tw/Resource/webdata/ 21717_1_20120808UniversalHealthCoverage.pdf.

9. Cheng $\mathrm{CL}$, Kao YH, Lin SJ, Lee $\mathrm{CH}$, Lai ML: Validation of the national health insurance research database with ischemic stroke cases in Taiwan. Pharmacoepidemiol Drug Saf 2011, 20:236-242.

10. Kim SG, Hong JM, Kim HY, Lee J, Chung PW, Park KY, Kim GM, Lee KH, Chung CS, Bang OY: Ischemic stroke in cancer patients with and without conventional mechanisms: a multicenter study in Korea. Stroke 2010, 41:798-801.

11. Timp JF, Braekkan SK, Versteeg HH, Cannegieter SC: Epidemiology of cancer-associated venous thrombosis. Blood 2013, 122:1712-1723.

12. Walker AJ, Card TR, West J, Crooks C, Grainge MJ: Incidence of venous thromboembolism in patients with cancer - a cohort study using linked United Kingdom databases. Eur J Cancer 2013, 49:1404-1413.

13. Matsushita H, Kurabayashi T, Tomita M, Yamamoto Y, Aoki Y, Tanaka K: Disseminated intravascular coagulation associated with intratumoral hemorrhage of ovarian cancer. Gynecol Obstet Invest 2001, 51:274-276.

14. Yokota N, Koizume S, Miyagi E, Hirahara F, Nakamura Y, Kikuchi K, Ruf W, Sakuma Y, Tsuchiya E, Miyagi Y: Self-production of tissue factor-coagulation factor VII complex by ovarian cancer cells. Br J Cancer 2009, 101:2023-2029.

15. Wang X, Wang E, Kavanagh JJ, Freedman RS: Ovarian cancer, the coagulation pathway, and inflammation. J Trans/ Med 2005, 3:25.

16. von Tempelhoff GF, Dietrich M, Niemann F, Schneider D, Hommel G, Heilmann L: Blood coagulation and thrombosis in patients with ovarian malignancy. Thromb Haemost 1997, 77:456-461.

17. Jovin TG, Boosupalli V, Zivkovic SA, Wechsler LR, Gebel JM: High titers of CA-125 may be associated with recurrent ischemic strokes in patients with cancer. Neurology 2005, 64:1944-1945.

18. Harmsen $P$, Lappas $G$, Rosengren A, Wilhelmsen L: Long-term risk factors for stroke: twenty-eight years of follow-up of 7457 middle-aged men in Goteborg, Sweden. Stroke 2006, 37:1663-1667.

19. Chu CN, Chen SW, Bai LY, Mou CH, Hsu CY, Sung FC: Increase in stroke risk in patients with head and neck cancer: a retrospective cohort study. Br J Cancer 2011, 105:1419-1423.

20. Chen PC, Muo CH, Lee YT, Yu YH, Sung FC: Lung cancer and incidence of stroke: a population-based cohort study. Stroke 2011, 42:3034-3039.

21. Huang YS, Lee CC, Chang TS, Ho HC, Su YC, Hung SK, Lee MS, Chou P, Chang $\mathrm{YH}$, Lee CC: Increased risk of stroke in young head and neck cancer patients treated with radiotherapy or chemotherapy. Oral Oncol 2011, 47:1092-1097.

22. Nilsson G, Holmberg L, Garmo H, Terent A, Blomqvist C: Increased incidence of stroke in women with breast cancer. Eur J Cancer 2005, 41:423-429.

23. Czaykowski PM, Moore MJ, Tannock IF: High risk of vascular events in patients with urothelial transitional cell carcinoma treated with cisplatin based chemotherapy. J Urol 1998, 160:2021-2024.

24. Ruiz MA, Marugan I, Estelles A, Navarro I, Espana F, Alberola V, San Juan L, Aznar J, Garcia-Conde J: The influence of chemotherapy on plasma coagulation and fibrinolytic systems in lung cancer patients. Cancer 1989, 63:643-648

25. Licciardello JT, Moake JL, Rudy CK, Karp DD, Hong WK: Elevated plasma von Willebrand factor levels and arterial occlusive complications associated with cisplatin-based chemotherapy. Oncology 1985 , 42:296-300.

26. Schilsky RL, Anderson T: Hypomagnesemia and renal magnesium wasting in patients receiving cisplatin. Ann Intern Med 1979, 90:929-931.

27. Manno EM: Magnesium sulphate and cerebral vasospasm. Lancet Neurol 2005, 4:329-330.

28. Eguchi R, Fujimori Y, Ohta T, Kunimasa K, Nakano T: Calpain is involved in cisplatin-induced endothelial injury in an in vitro three-dimensional blood vessel model. Int J Oncol 2010, 37:1289-1296.
29. Periard D, Boulanger CM, Eyer S, Amabile N, Pugin P, Gerschheimer C, Hayoz D: Are circulating endothelial-derived and platelet-derived microparticles a pathogenic factor in the cisplatin-induced stroke? Stroke 2007, 38:1636-1638.

30. Yen T, Walsh JD, Pejler G, Berndt MC, Geczy CL: Cisplatin-induced platelet activation requires mononuclear cells: role of GMP-140 and modulation of procoagulant activity. Br J Haematol 1993, 83:259-269.

31. Li SH, Chen WH, Tang Y, Rau KM, Chen YY, Huang TL, Liu JS, Huang CH: Incidence of ischemic stroke post-chemotherapy: a retrospective review of 10,963 patients. Clin Neurol Neurosurg 2006, 108:150-156.

32. Martin GG, Fernandez SP, Castro VS, Cueto OH, Acebal MR: Vertebral artery occlusion after chemotherapy. Stroke 2008, 39:e38. Author reply e39.

33. Provencio M, Bonilla F, Lacasta A, Espana P: Cerebral infarction after cisplatin-based chemotherapy. Postgrad Med J 1994, 70:525-526.

34. Seng S, Liu Z, Chiu SK, Proverbs-Singh T, Sonpavde G, Choueiri TK, Tsao CK, Yu M, Hahn NM, Oh WK, Galsky MD: Risk of venous thromboembolism in patients with cancer treated with cisplatin: a systematic review and meta-analysis. J Clin Oncol 2012, 30:4416-4426.

35. Tsai SJ, Huang YS, Tung CH, Lee CC, Lee MS, Chiou WY, Lin HY, Hsu FC, Tsai $\mathrm{CH}$, Su YC, Hung SK: Increased risk of ischemic stroke in cervical cancer patients: a nationwide population-based study. Radiat Oncol 2013, 8:41.

36. Jagsi R, Griffith KA, Koelling T, Roberts R, Pierce $L$ : Stroke rates and risk factors in patients treated with radiation therapy for early-stage breast cancer. J Clin Oncol 2006, 24:2779-2785.

37. De Bruin ML, Dorresteijn LD, van't Veer MB, Krol AD, van der Pal HJ, Kappelle AC, Boogerd W, Aleman BM, van Leeuwen FE: Increased risk of stroke and transient ischemic attack in 5-year survivors of Hodgkin lymphoma. J Natl Cancer Inst 2009, 101:928-937.

doi:10.1186/1741-7015-12-53

Cite this article as: Kuan et al:: Risk of ischemic stroke in patients with ovarian cancer: a nationwide population-based study. BMC Medicine 2014 12:53.

\section{Submit your next manuscript to BioMed Central and take full advantage of:}

- Convenient online submission

- Thorough peer review

- No space constraints or color figure charges

- Immediate publication on acceptance

- Inclusion in PubMed, CAS, Scopus and Google Scholar

- Research which is freely available for redistribution

Submit your manuscript at www.biomedcentral.com/submit
C Biomed Central 